\title{
Treating buried bumper percutaneous endoscopic gastrostomy tubes: Outcomes and complications of removal
}

\author{
A. T. Cole, J. Bebb, M. Patrick, L. Odell, S. Cole and R. N. Cunliffe \\ Derby City General Hospital, Derby NHS Foundation Trust, Uttoxeter Rd, Derby DE22 3NE, UK
}

Buried bumper syndrome is a recognised complication of percutaneous endoscopic gastrostomy (PEG) which leads to failure of feeding as the flange of the gastrostomy tube becomes overgrown by the mucosal layer of the stomach. In the case of PEG tubes that usually require endoscopic removal, buried bumpers can be removed either endoscopically or surgically. We present our results of treating buried bumper in our unit.

Cases of buried bumper were identified from our Nutrition team database. We undertook a retrospective case-note review to determine outcomes and complications. Buried bumpers were removed either surgically or endoscopically. Endoscopic techniques used were either a pull or a push technique. Each of these was combined with radial cuts of the overgrown mucosa using needle or insulated tip knife and argon plasma coagulation. Jejunal extension tubes, fitted via the PEG, were used for feeding until successful PEG replacement was achieved.

Despite a programme of education for nursing homes and carers, twelve cases of buried bumper were found between April 2005 and June 2007 (seven male, five female, median age 62 (range 35-85) years). Models of PEG were Freka size 15 French in eleven patients and size 9 French in one patient. Indications for PEG insertion were post stroke in eight patients, other neurological cause in four patients. Prior to endoscopy all patients underwent assessment by CT scan and two had PEGograms. Two patients died prior to attempted treatment. Ten patients had attempted endoscopy. Two patients could not be intubated. Attempts were made at endoscopic removal in eight cases. Six buried bumpers were successfully removed endoscopically, taking between one and five gastroscopies each (median 3 , pull technique used in one case with size 9 French PEG). Two of these patients had antibiotics for pneumonia 2 and $19 \mathrm{~d}$ post-procedure and one for a non specific febrile illness. Four PEG were removed surgically. Of these one patient had a prolonged ITU stay.

Endoscopic removal of buried PEG bumpers is possible in many patients though they often need more than one endoscopic session. Jejunal extension tubes can be used to ensure adequate gastric access between procedures. Surgical removal is an alternative but not without complications. Chest infections may complicate either surgical or endoscopic removal. 